\title{
Optimization of the Inventory Control Model of Auto Enterprise Parts Based on AHP
}

\author{
Wang Xue-Lian \\ College of Engineering Technology \\ Jilin Agricultural University \\ Changchun Jilin, China \\ E-mail:37311548@qq.com
}

\author{
Li Xiao-Ling \\ Tianjin Petroleum Vocational and Technical College \\ line 2: name of organization, acronyms acceptable \\ Tianjin, China \\ E-mail: 44695597@qq.com
}

\begin{abstract}
In order to solve inventory control problems of auto parts in automobile industry, such as overstock, stock capital was exorbitant and so on; Value, stock out loss degree, purchasing lead time, profit rate and demand rate were selected as the evaluation criterion. At the same time, taken into account the difference of operational characteristics between the auto parts and repair parts of manufacturing enterprises auto parts were divided into quick-wear parts, repair parts, basic parts, and accident parts in accordance with consumption rule. The optimization model based on AHP was set up and analyzed. Finally, Auto parts were re- classified with the sequencing result of combined weights and $\mathrm{ABC}$ method in order to control them in different degree. Consistence Ratio C.R. $=0.0469<0.1$, the global consistency of the judgment matrix was acceptable. The four parts were ordered according to the combined weights, that was B3> B4> B2> B1. Compared with traditional inventory control methods, more influence factors were considered, the hierarchical structure model with auto parts characteristics was set up which would make the parts classification more accurate and the inventory structure more reasonable.
\end{abstract}

Keywords-analytic hierarchy process (AHP); inventory control; ABC classification; optimization; combined weight

\section{INTRODUCTION}

In recent years, with the rapid growth of car ownership Auto parts sales also increased and traditional management methods made the automobile manufacturing enterprises expose many problems in the spare parts inventory control such as the backlog of inventory and the "dead stock" phenomenon, these caused the spare parts stock engross too large, but at the same time parts shortage phenomenon often occurred, response speed was slow, customer satisfaction declined. Investigate its reason, among them a very important link is the unreasonable structure of spare parts inventory.

At present, a broader application of the control measure is ABC analysis method. The method obtained a lot of automobile manufacturing enterprise's favor because its operation is simple and convenient. But the classification criteria of $\mathrm{ABC}$ analysis method is too single, usually only taking the inventory amount as the standard of classification, there are some limitations, thus affecting the other parts of inventory management ${ }^{[1,2]}$. Analytic hierarchy process (AHP) as a practical and multi criteria decision making tool, has been widely used in various fields at home and abroad. More accurate decisions can be made through AHP applied to inventory management with the analysis of influence factors of material management by the combination of quantity and quality ${ }^{[3]}$. Therefore, in order to control the inventory more targeted, Analytic hierarchy process was used to optimize the traditional $\mathrm{ABC}$ analysis method in this paper, the inventory control model of Auto parts was rebuilt, the sorted parts were classified again by the hierarchy analysis results combined with $\mathrm{ABC}$ method, so then the more accurate inventory amount can be controlled.

\section{ANALYTIC HIERARCHY PROCESS}

Analytic hierarchy process is a system analysis method proposed by Professor Thomas L. Saaty from University of Pittsburgh America in twentieth Century 70' $\mathrm{s}$ [4]. This method gives the preferential order of alternatives by representing a complex decision problem as an ordered hierarchical structure and making use of people's subjective judgment and scientific computing. This subsection provides a brief introduction to the basic steps of analytic hierarchy process.

\section{A. Establishing the hierarchical structure model}

First, define the problem need to be analyzed and decided, and get it organized, hierarchical, then set up stratum structure model. The hierarchical structure models of AHP are mainly divided into the following three levels:

- Target layer (Highest level): The purpose of decision and the problem need to be solved.

- Criteria Layer (Middle level): Factors considered, decision criteria.

- Alternative layer (Lowest level): Alternatives to the decision-making.

\section{B. Constructing judgment matrix (pairwise comparison)}

Aiming at all elements of each layer, the relative significances are compared by using the paired comparison method, and then the decision maker's preference judgments are quantified according to ratio scale of AHP in Table I, judgment matrix is formed [4].

Let judgment matrix compared be $\mathrm{A}=\left(\mathrm{a}_{i j}\right)_{n \times n}$, judgment matrix $\mathrm{A}$ has the following properties:

$$
\begin{array}{ll}
\text { - } & \mathrm{a}_{i j}>0 ; \\
\text { - } & \mathrm{a}_{j i}=1 / \mathrm{a}_{i j} ; \\
\text { - } & \mathrm{a}_{i i}=1 ;
\end{array}
$$


- The greater the value of $\mathrm{a}_{i j}$, the greater the importance of factor $i$ to factor $j$.

TABLE I. THE RATIO SCALE OF AHP

\begin{tabular}{|c|l|}
\hline Ratio scale & \multicolumn{1}{c|}{ Meaning } \\
\hline 1 & Equally Importance \\
\hline 3 & Moderately More Importance \\
\hline 5 & Strongly More Importance \\
\hline 7 & Very Strongly Importance \\
\hline 9 & Extremely Importance \\
\hline $2,4,6,8$ & $\begin{array}{l}\text { The compromise value between the above } \\
\text { standards }\end{array}$ \\
\hline Reciprocal & $\begin{array}{l}\text { If the importance ratio of factor } i \text { to factor } j \text { is } \\
\mathrm{a}_{i j}, \text { then the importance ratio of factor } j \text { to } \\
\text { factor } i \text { is } \mathrm{a}_{j i}=1 / \mathrm{a}_{i j}\end{array}$ \\
\hline
\end{tabular}

The value of $\mathrm{a}_{i j}$ in the matrix is determined after repeated research according to the data combined with expert advice and experience of professional analysis persons.

\section{Level simple sequence and consistency check}

Level simple sequence means the importance order of each factor of the layer for some factor of upper layer (i.e. the weight value) [4].

The step is to compute the eigenvalue and eigenvector met $\mathrm{Aw}=\lambda$ maxw for judgment matrix $\mathrm{A}$. Where $\lambda$ max is the maximum eigenvalue of $\mathrm{A}, \mathrm{W}$ is the eigenvector corresponding to $\lambda \max$, the component $\omega \mathrm{i}$ of $\mathrm{w}$ is the single ranking weight value of related factor.

Level simple sequence whether can be identified need consistency check. Consistency check refers to determine the allowable range for $\mathrm{A}$. Only through the inspection can illustrate the judgment matrix is reasonable logically and continue the analysis of the results.

The steps of consistency check are as follows:

Step 1 Compute C.I. (Consistency Index)

$$
\text { C.I. }=\frac{\lambda \max -n}{n-1}
$$

Step2 Look-up Table to determine the corresponding R.I.(Random Consistency Index) ${ }^{[4]}$, concrete values are shown in Table II.

TABLE II. RANDOM CONSISTENCY INDEX (R.I.)

\begin{tabular}{|c|c|c|c|c|c|c|c|c|}
\hline Order & 3 & 4 & 5 & 6 & 7 & 8 & 9 & 10 \\
\hline R.I. & 0.58 & 0.89 & 1.12 & 1.24 & 1.32 & 1.41 & 1.45 & 1.49 \\
\hline
\end{tabular}

Step 3 Compute C.R.(Consistence Ratio)and make a judgment.

$$
\text { C.R. }=\text { C.I. } / \text { R.I. }
$$

When C.R. $<0.1 \quad A$ is called the satisfactory consistency matrix and when C.R.>0.1 A is not consistent that judgment matrix is inconsistent with consistency requirements and need to readjust.

\section{Level total sequence and consistency check}

Calculating relative importance weight value of all the factors of a layer to the top layer (the total target) is called level total sequence ${ }^{[4]}$. This process is carried out successively from the highest level to the lowest level.
If layer A contains $m$ elements $\mathrm{A}_{1}, \mathrm{~A}_{2}, \ldots, \mathrm{A}_{m}$ the total weights of the layer are $\mathrm{a}_{1}, \mathrm{a}_{2}, \ldots, \mathrm{a}_{m}$; Next layer $\mathrm{B}$ contains $n$ elements $\mathrm{B}_{1}, \mathrm{~B}_{2}, \ldots, \mathrm{B}_{n}$, the weights to the factor $\mathrm{A}_{j}$ are $\mathrm{b}_{1 j}, \mathrm{~b}_{2 j}, \ldots, \mathrm{b}_{n j}$, the synthetic weights of layer $\mathrm{B}$ to layer A are:

$$
\sum_{j=1}^{m} a_{j} b_{i j} \quad(\mathrm{i}=1,2, \ldots, \mathrm{n})
$$

In order to evaluate the consistency of level total sequence results, consistency check is also required similar to level simple sequence. Therefore, the following indicators need to be calculated:

$$
\begin{aligned}
& \text { C.I. }=\sum_{j=1}^{m} a_{j} \text { C.I. }{ }_{j} \\
& \text { R.I. }=\sum_{j=1}^{m} a_{j} \text { R.I. }_{j} \\
& \text { C.R. }=\text { C.I./R.I. }
\end{aligned}
$$

Where, C.I. is the consistence index of level total sequence, C.I. is the consistence index of the judgment matrix in the layer corresponding with $a_{j}$, R.I. is the random consistence index of level total sequence, R.I..$_{j}$ is the random consistence index of the judgment matrix in the layer corresponding with $\mathrm{a}_{j}, \mathrm{C} . \mathrm{R}$. is the consistence ratio of level total sequence. As level simple sequence, When C.R. $<0.1$, the results of level total sequence are consistent; Otherwise, the judgment matrixes of the level need to be adjusted, until consistency check of level total sequence meet the requirements. Finally, the final decision is made according to level total sequence of the lowest layer (alternative layer).

\section{BUILDING OF THE OPTIMIZING MODEL OF INVENTORY CONTROL}

\section{A. Establishing a hierarchical structure model of auto parts inventory control}

Previous study on inventory control of AHP was mostly aimed at repair parts of manufacturing enterprise or a class of spare parts, the parts was analyzed directly as alternative layer elements. However, auto parts are quite different from them in the consumption rule and application characteristics then matrix judgment and solving weight for each part are impossible. Therefore, in order to convenient operation of enterprises the auto parts were divided into quick-wear parts, repair parts, basic parts, and accident parts as the alternative layer elements before being analyzed according to the lifetime of the vehicle and the consumption rule of parts, also through investigation on many automobile manufacturing enterprises ${ }^{[5-9]}$.

Three layers hierarchy structure model of auto parts were built. Target layer $\mathrm{Z}$ is determining the stock structure; Criteria Layer A is five evaluation Criterions influenced importantly on the auto parts according to investigation on automobile manufacturing enterprises: value $A_{1}$, stock out loss degree $A_{2}$, purchasing lead time $A_{3}$, profit rate $A_{4}$, demand rate $A_{5}$; Alternative layer $\mathrm{B}$ is four categories of quick-wear parts 
$\mathrm{B}_{1}$, repair parts $\mathrm{B}_{2}$, basic parts $\mathrm{B}_{3}$, and accident parts $\mathrm{B}_{4}$, See Fig.1.

Target layer

Determining the stock structure $\mathrm{Z}$

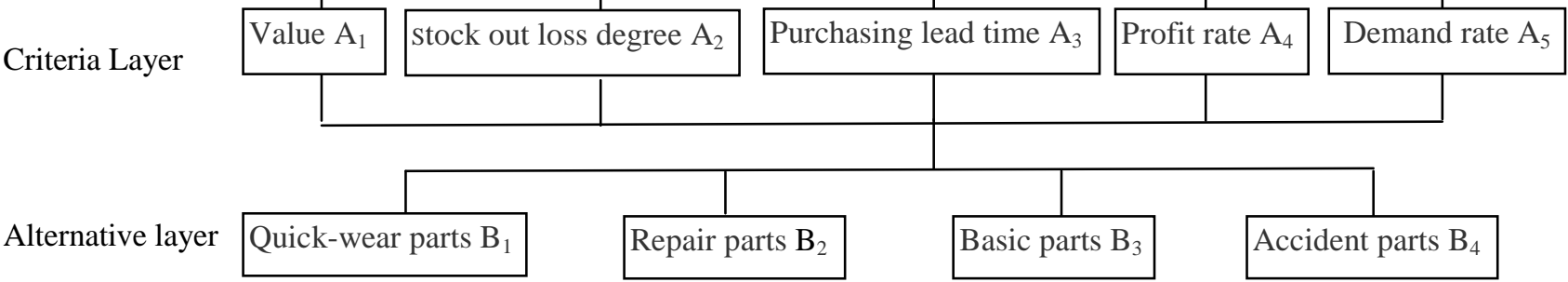

Figure 1. Hierarchical structure model of auto parts

\section{B. Constructing judgment matrix of Criteria Layer A to} Target layer $Z$ and consistency check

In order to get more accurate judgment matrix, the scores of the relative importance of each factor were given by the professionals according to AHP scale method then judgment matrix was constructed, see Table III.

TABLE III. JUDGMENT MATRIX OF CRITERIA LAYER TO TARGET LAYER

\begin{tabular}{|c|c|c|c|c|c|}
\hline Z-A & A1 & A2 & A3 & A4 & A5 \\
\hline A1 & 1 & 3 & 7 & 5 & 4 \\
\hline A2 & $1 / 3$ & 1 & 5 & 3 & 2 \\
\hline $\mathbf{A 3}$ & $1 / 7$ & $1 / 5$ & 1 & $1 / 4$ & $1 / 5$ \\
\hline $\mathbf{A 4}$ & $1 / 5$ & $1 / 3$ & 4 & 1 & $1 / 3$ \\
\hline $\mathbf{A 5}$ & $1 / 4$ & $1 / 2$ & 5 & 3 & 1 \\
\hline
\end{tabular}

Eigenvector $\mathrm{w}$ and maximum eigenvalue $\lambda_{\max }$ are solved by square root method in this paper ${ }^{[4,10]}$.

Step1 Calculate the product of each row element in the judgment matrix, i.e.

$$
m_{i}=\prod_{j=1}^{5} a_{i j}, i=1,2, \cdots, 5
$$

Step 2 Calculate the 5 th Roots of $m_{i}$, i.e.

$$
\begin{aligned}
& \overline{w_{i}}=\sqrt[5]{m_{i}}, i=1,2, \cdots, 5 \\
& \bar{w}=\left(\overline{w_{1}}, \overline{w_{2}}, \cdots, \overline{w_{5}}\right)^{T}
\end{aligned}
$$

Step3 Through normalization processing of vector $\bar{w}$ 错误!未找到引用源。 weights of criterion layer to target layer were got, i.e.

$$
w=\overline{w_{i}} / \sum_{k=1}^{5} \overline{w_{k}}, i=1,2, \cdots, 5
$$

Step4 Calculating maximum eigenvalue, i.e.

$$
\lambda_{\max }=\frac{1}{5} \sum_{i=1}^{5} \frac{(A w)_{i}}{w}
$$

The above calculation processes were carried out through the MATLAB ${ }^{[11]}$, the results were that $\lambda_{\max }=5.2681$, the weight values of criterion layer to target layer see Table IV.

TABLE IV. THE WEIGHTS OF CRITERIA LAYER TO TARGET LAYER

\begin{tabular}{|c|c|c|c|c|c|}
\hline Criterion & $\mathrm{A}_{1}$ & $\mathrm{~A}_{2}$ & $\mathrm{~A}_{3}$ & $\mathrm{~A}_{4}$ & $\mathrm{~A}_{5}$ \\
\hline Weight & 0.4814 & 0.2280 & 0.0388 & 0.0886 & 0.1631 \\
\hline
\end{tabular} Consistency check:
Cons

C.I. $=(5.2681-5) /(5-1)=0.0670$,

5 th order R.I. was got by looking up Table II,

R.I. $=1.12$,

C.R. $=$ C.I. $/$ R.I. $=0.0670 / 1.12=0.0598<0.1$, thus the matrix has satisfied consistency.

\section{Constructing judgment matrix of Alternative layer $B$ to Criteria Layer A and consistency check}

In the same way, judgment matrixes of five criterions were set up then parameters $w, \lambda_{\max }$, C.I. and C.R. of the judgment matrixes were calculated, and the results were shown in Table V-Table IX.

TABLE V. THE JUDGMENT MATRIX OF VALUE $\mathrm{A}_{1}$

\begin{tabular}{|c|c|c|c|c|c|}
\hline $\mathbf{A}_{\mathbf{1}}-\mathbf{B}$ & $\mathbf{B}_{\mathbf{1}}$ & $\mathbf{B}_{\mathbf{2}}$ & $\mathbf{B}_{\mathbf{3}}$ & $\mathbf{B}_{\mathbf{4}}$ & $\boldsymbol{w}$ \\
\hline $\mathbf{B}_{\mathbf{1}}$ & 1 & $1 / 2$ & $1 / 7$ & $1 / 5$ & 0.0612 \\
\hline $\mathbf{B}_{\mathbf{2}}$ & 2 & 1 & $1 / 5$ & $1 / 3$ & 0.1070 \\
\hline $\mathbf{B}_{\mathbf{3}}$ & 7 & 5 & 1 & 3 & 0.5669 \\
\hline $\mathbf{B}_{\mathbf{4}}$ & 5 & 3 & $1 / 3$ & 1 & 0.2648 \\
\hline \multicolumn{7}{|c|}{$\lambda_{\max }=4.0685$ C.I. $=0.0228 \quad \mathrm{CR}=0.0257<0.1$} \\
\hline
\end{tabular}

TABLE VI. THE JUDGMENT MATRIX OF STOCK OUT LOSS DEGREE A

\begin{tabular}{|c|c|c|c|c|c|}
\hline $\mathbf{A}_{\mathbf{2}}-\mathbf{B}$ & $\mathbf{B}_{\mathbf{1}}$ & $\mathbf{B}_{\mathbf{2}}$ & $\mathbf{B}_{\mathbf{3}}$ & $\mathbf{B}_{\mathbf{4}}$ & $\boldsymbol{w}$ \\
\hline $\mathbf{B}_{\mathbf{1}}$ & 1 & $1 / 2$ & $1 / 4$ & $1 / 5$ & 0.0761 \\
\hline $\mathbf{B}_{\mathbf{2}}$ & 2 & 1 & $1 / 2$ & $1 / 3$ & 0.1454 \\
\hline $\mathbf{B}_{\mathbf{3}}$ & 4 & 2 & 1 & $1 / 5$ & 0.2153 \\
\hline $\mathbf{B}_{\mathbf{4}}$ & 5 & 3 & 5 & 1 & 0.5632 \\
\hline \multicolumn{7}{|c|}{$\lambda_{\max }=4.2199$} & C.I. $=0.0733 \quad \mathrm{CR}=0.0824<0.1$ \\
\hline
\end{tabular}

TABLE VII. THE JUDGMENT MATRIX OF PURCHASING LEAD TIME $\mathrm{A}_{3}$

\begin{tabular}{|c|c|c|c|c|c|}
\hline $\mathbf{A}_{\mathbf{3}}-\mathbf{B}$ & $\mathbf{B}_{\mathbf{1}}$ & $\mathbf{B}_{\mathbf{2}}$ & $\mathbf{B}_{\mathbf{3}}$ & $\mathbf{B}_{\mathbf{4}}$ & $\boldsymbol{w}$ \\
\hline $\mathbf{B}_{\mathbf{1}}$ & 1 & $1 / 2$ & $1 / 6$ & $1 / 5$ & 0.0655 \\
\hline $\mathbf{B}_{\mathbf{2}}$ & 2 & 1 & $1 / 5$ & $1 / 4$ & 0.1026 \\
\hline $\mathbf{B}_{\mathbf{3}}$ & 6 & 5 & 1 & 2 & 0.5076 \\
\hline $\mathbf{B}_{\mathbf{4}}$ & 5 & 4 & $1 / 2$ & 1 & 0.3243 \\
\hline \multicolumn{7}{|c|}{$\lambda_{\max }=4.0605$ C.I. $=0.0202 \quad \mathrm{CR}=0.0227<0.1$} \\
\hline
\end{tabular}

TABLE VIII. THE JUDGMENT MATRIX OF PROFIT RATE $\mathrm{A}_{4}$

\begin{tabular}{|c|c|c|c|c|c|}
\hline $\mathbf{A}_{\mathbf{4}}-\mathbf{B}$ & $\mathbf{B}_{\mathbf{1}}$ & $\mathbf{B}_{\mathbf{2}}$ & $\mathbf{B}_{\mathbf{3}}$ & $\mathbf{B}_{\mathbf{4}}$ & $\boldsymbol{w}$ \\
\hline $\mathbf{B}_{\mathbf{1}}$ & 1 & $1 / 4$ & $1 / 7$ & $1 / 5$ & 0.0565 \\
\hline $\mathbf{B}_{\mathbf{2}}$ & 4 & 1 & $1 / 2$ & $1 / 3$ & 0.1755 \\
\hline $\mathbf{B}_{\mathbf{3}}$ & 7 & 2 & 1 & 2 & 0.4467 \\
\hline $\mathbf{B}_{\mathbf{4}}$ & 5 & 3 & $1 / 2$ & 1 & 0.3214 \\
\hline \multicolumn{7}{|c|}{$\lambda_{\max }=4.1350 \quad$ C.I. $=0.0450 \quad$ CR $=0.0506<0.1$} \\
\hline
\end{tabular}

From the above results, 5 C.R. values were less than 0.1 , so the level of satisfaction was achieved. 
TABLE IX. THE JUDGMENT MATRIX OF DEMAND RATE $\mathrm{A}_{5}$

\begin{tabular}{|c|c|c|c|c|c|}
\hline $\mathbf{A}_{\mathbf{5}}-\mathbf{B}$ & $\mathbf{B}_{\mathbf{1}}$ & $\mathbf{B}_{\mathbf{2}}$ & $\mathbf{B}_{\mathbf{3}}$ & $\mathbf{B}_{\mathbf{4}}$ & $\boldsymbol{w}$ \\
\hline $\mathbf{B}_{\mathbf{1}}$ & 1 & 3 & 7 & 4 & 0.5432 \\
\hline $\mathbf{B}_{\mathbf{2}}$ & $1 / 3$ & 1 & 5 & 3 & 0.2683 \\
\hline $\mathbf{B}_{\mathbf{3}}$ & $1 / 7$ & $1 / 5$ & 1 & $1 / 4$ & 0.0522 \\
\hline $\mathbf{B}_{\mathbf{4}}$ & $1 / 4$ & $1 / 3$ & 4 & 1 & 0.1363 \\
\hline \multicolumn{7}{|c|}{$\lambda_{\max }=4.1704$ C.I. $=0.0568 \quad \mathrm{CR}=0.0638<0.1$} \\
\hline
\end{tabular}

\section{Calculating combined weight of alternative layer to target layer}

Combined weights of alternative layer to target layer were obtained by the formula (3), the results were shown in Table X.

TABLE X. THE COMBINED WEIGHT OF ALTERNATIVE LAYER TO TARGET LAYER

\begin{tabular}{|c|c|c|c|c|c|c|}
\hline Z-B & $\mathbf{A}_{\mathbf{1}}$ & $\mathbf{A}_{\mathbf{2}}$ & $\mathbf{A}_{\mathbf{3}}$ & $\mathbf{A}_{\mathbf{4}}$ & $\mathbf{A}_{\mathbf{5}}$ & Synthetic Weight \\
\hline $\boldsymbol{w}$ & 0.4814 & 0.2280 & 0.0388 & 0.0886 & 0.1631 \\
\hline C.I. & 0.0228 & 0.0733 & 0.0202 & 0.0450 & 0.0568 \\
\hline $\mathbf{B}_{\mathbf{1}}$ & 0.0612 & 0.0761 & 0.0655 & 0.0565 & 0.5432 \\
\hline $\mathbf{B}_{\mathbf{2}}$ & 0.1070 & 0.1454 & 0.1026 & 0.1755 & 0.1430 \\
\hline $\mathbf{B}_{\mathbf{3}}$ & 0.5669 & 0.2153 & 0.5076 & 0.4467 & 0.1480 & 0.2683 \\
\hline $\mathbf{B}_{\mathbf{4}}$ & 0.2648 & 0.5632 & 0.3243 & 0.3214 & 0.1363 & 0.3192 \\
\hline
\end{tabular}

Do the consistency check to the combined weights based on formula(4)- formula(6):

$$
\begin{aligned}
\text { C.I. }= & {\left[\begin{array}{llll}
0.0228 & 0.0733 & 0.0202 & 0.0450 \\
& 0.0568
\end{array}\right]^{*} \mathrm{~W}=0.0417 }
\end{aligned}
$$

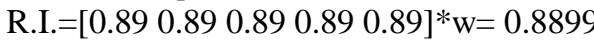

C.R. $=$ C.I. $/$ R.I. $=0.0469<0.1$

Thus the global consistency of the judgment matrix was acceptable.

\section{E. ABC classification after Sorting of the combined weight}

The four parts were ordered according to the combined weights, that was $B_{3}>B_{4}>B_{2}>B_{1}$, then the sorted parts were classified based on the $\mathrm{ABC}$ method to control inventory more accurately.

This paper took 25 randomly selected parts of red flag series car from inventory report as an example, the parts were classified according to $\mathrm{ABC}$ method with inventory amount as the standard before optimization and the calculation will not be discussed. Classification was made according to sorting of the combined weights after optimization based on the AHP. First, attribute of the 25 parts was divided that was each part should belong to quick-wear parts, repair parts, basic parts, or accident parts then the combined weight was imposed on them and classified; Due to its computational process had been considered a factor value in AHP, so combined weight multiplied by the stock quantity obtained weight stock quantity in the next classification, and cumulate percents were calculated, final classification was made according to the standard of $\mathrm{ABC}$, the results of classification after the optimization, see Table XI.

\begin{tabular}{|c|c|c|c|c|c|c|c|c|c|c|}
\hline 4 & A & B & C & D & $\mathrm{E}$ & F & G & $\mathrm{H}$ & I & $\mathrm{J}$ \\
\hline 1 & No. & Name & $\begin{array}{c}\text { Classification } \\
\text { before } \\
\text { optimization }\end{array}$ & Ownership & Combined weight & $\begin{array}{l}\text { Price } \\
\text { (yuan) }\end{array}$ & $\mid \begin{array}{c}\text { Stock quantity } \\
\text { (piece) }\end{array}$ & $\begin{array}{l}\text { Weight stock } \\
\text { quantity }\end{array}$ & $\begin{array}{c}\text { Cumvlate } \\
\text { percent }\end{array}$ & $\begin{array}{c}\text { Classification after } \\
\text { optimization }\end{array}$ \\
\hline 2 & 1 & Body assembly & A & accident parts & 0.3192 & 44401.5 & 2 & 0.6384 & $0.05 \%$ & A \\
\hline 3 & 2 & CD avdio assembly & A & basic parts & 0.3898 & 3860.41 & 6 & 2.3388 & $0.21 \%$ & A \\
\hline 4 & 3 & Driver's seat & A & basic parts & 0.3898 & 7381.59 & 6 & 2.3388 & $0.37 \%$ & $\mathrm{~A}$ \\
\hline 5 & 4 & Transmission Case & A & basic parts & 0.3898 & 5187.72 & 7 & 2.7286 & $0.56 \%$ & A \\
\hline 6 & 5 & Throttle valve connector & A & basic parts & 0.3898 & 4283.01 & 8 & 3.1184 & $0.78 \%$ & A \\
\hline 7 & 6 & Windshield & A & accident parts & 0.3192 & 2534.4 & 13 & 4.1496 & $1.07 \%$ & $\mathrm{~A}$ \\
\hline 8 & 7 & Rear seat cushion & A & basic parts & 0.3898 & 558.52 & 21 & 8.1858 & $1.65 \%$ & A \\
\hline 9 & 8 & Ignition coil & A & quick-wear parts & 0.143 & 662.84 & 74 & 10.582 & $2.39 \%$ & A \\
\hline 10 & 9 & Rrear bumper & A & accident parts & 0.3192 & 997.78 & 35 & 11.172 & $3.18 \%$ & $\mathrm{~A}$ \\
\hline 11 & 10 & Front brake & A & quick-wear parts & 0.143 & 706.56 & 81 & 11.583 & $3.99 \%$ & A \\
\hline 12 & 11 & Generator & A & basic parts & 0.3898 & 1062.01 & 37 & 14.4226 & $5.00 \%$ & A \\
\hline 13 & 12 & Tire & A & quick-wear parts & 0.143 & 476.38 & 113 & 16.159 & $6.14 \%$ & B \\
\hline 14 & 13 & Gear shaft & B & repair parts & 0.148 & 188.98 & 117 & 17.316 & $7.36 \%$ & B \\
\hline 15 & 14 & Starter & A & basic parts & 0.3898 & 1187.8 & 45 & 17.541 & $8.59 \%$ & B \\
\hline 16 & 15 & Crankshaft oil seal & A & repair parts & 0.148 & 166.27 & 142 & 21.016 & $10.07 \%$ & B \\
\hline 17 & 16 & Fuel pipe & A & quick-wear parts & 0.143 & 151.99 & 175 & 25.025 & $11.83 \%$ & B \\
\hline 18 & 17 & Oil pump pad & B & quick-wear parts & 0.143 & 43.12 & 219 & 31.317 & $14.03 \%$ & B \\
\hline 19 & 18 & Brake disc & B & quick-wear parts & 0.143 & 100.93 & 268 & 38.324 & $16.73 \%$ & B \\
\hline 20 & 19 & Antifreeze & B & repair parts & 0.148 & 63.04 & 329 & 48.692 & $20.16 \%$ & C \\
\hline 21 & 20 & Car logo & $\mathrm{C}$ & quick-wear parts & 0.143 & 21.73 & 386 & 55.198 & $24.04 \%$ & $\mathrm{C}$ \\
\hline 22 & 21 & Air inlet pipe & B & quick-wear parts & 0.143 & 47.65 & 405 & 57.915 & $28.11 \%$ & $\mathrm{C}$ \\
\hline 23 & 22 & Oil filter & $\mathrm{C}$ & repair parts & 0.148 & 23.44 & 401 & 59.348 & $32.29 \%$ & $\mathrm{C}$ \\
\hline 24 & 23 & Timing belt & B & quick-wear parts & 0.143 & 34.94 & 419 & 59.917 & $36.51 \%$ & $\mathrm{C}$ \\
\hline 25 & 24 & Fuse & $\mathrm{C}$ & quick-wear parts & 0.143 & 6.44 & 1430 & 204.49 & $50.90 \%$ & $\mathrm{C}$ \\
\hline 26 & 25 & Rivet & $\mathrm{C}$ & quick-wear parts & 0.143 & 1.8 & 4880 & 697.84 & $100.00 \%$ & $\mathrm{C}$ \\
\hline
\end{tabular}

TABLE XI. FINAL CLASSIFICATION RESULTS 
Comparison of results before and after optimization showed some parts category changed, which was the result of comprehensive consideration of influence factors such as value, stock out loss degree, purchasing lead time, profit rate, demand rate and stock quantity. For example, tyres were classified originally as class A because of higher value that required fine management, but because they belonged to quick-wear parts, the demand rate was higher and easier to predict so into class B after the optimization, general management would be made, enterprises don't need to invest too much energy.

\section{CONCLUSION}

Inventory control model of auto parts was optimized by AHP in this paper and the factors such as value, stock out loss degree, purchasing lead time, profit rate, demand rate were considered; In addition, the previous research in the inventory management of AHP mostly aimed at maintenance spare parts of production enterprise or a category of spare parts, while auto parts were different from them in the consumption rule and application characteristics thus could not be generalized. Therefore, the auto parts were divided into quick-wear parts, repair parts, basic parts, and accident parts as the alternative layer elements, this is more in line with the actual situation of enterprises, and simplify the operation process. Compared with the previous inventory control methods, the traditional single classification criterion was changed, a hierarchical structure model with the characteristics of auto parts was constructed which can make inventory structure of the parts more reasonable and solve the problems of overstock effectively. Enterprises can adjust the corresponding indexes according to its actual situation in application.

\section{ACKNOWLEDGMENT}

Supported by Youth Foundation of Jilin Agricultural University (Grant No.201314)

\section{REFERENCES}

[1] Hadi-Vencheh, "An Improvement to Multiple Criteria ABC Inventory Classification," European Journal of Operational Research. vol. 201, 2010, pp. 962-965.

[2] Zhang J H and Li J H, "On Inventory Management Based on the Analytic Hierarchy Process and Activity Based Classification,"Mechanical Management and Development, vol. 120, April 2011, pp. 154-155.

[3] Thomas L Saaty, "Relative Measurement and Its Generalization in Decision Making: Why Pair Wise Comparisons are Central in Mathematics for the Measurement of Intangible Factors - the Analytic Hierarchy/network Process," RACSAM (Review of the Royal Spanish Academy of Sciences, Series A, Mathematics) vol. 102, 2008, pp. 251-318.

[4] Zhang B J, Analytic Hierarchy Process and Application.Beijing:Publishing House of Electronics Industry,2014.

[5] Xi X Y, Gao J J and Wang F D, "Classification Model for Inventory Management of Spare Parts Based on Analytic Hierarchy Process and Its Application,'Petroleum Engineering Construction, vol. 38,Feb. 2012, pp. 77-80.

[6] Feng Y, Yin D and Luo B, "ABC Classification Based on AHP in Rarely Used Spare Parts,"Computer and Dig ital Engineering, vol. 39, 2011, pp. 39-43.

[7] Ma Y X and Zhang Z G, "ABC Classification Model of Aircraft Spares Based on AHP and Fuzzy Evaluation," Logistics Technology, vol. 27, 2008, pp. 130-133.

[8] Sun F Y, Auto Parts and Marketing .Beijing:Machinery Industry Press, 2011.

[9] Jin T, "Research on Automobile Spare Parts Inventory Classification of SK Company,'Wuhan: Huazhong University of Science and Technology, 2011.

[10] Deng X, Li J M and Zeng H J, "Research on Computation Methods of AHP Weight Vector,"Mathematics in Practice and Theory, vol. 42, April 2012, pp. 93-100.

[11] Zhuo J W, Wei Y S and Qin J, Application of Matlab in Mathematical Modeling.Beijing: Beihang University press,2013. 